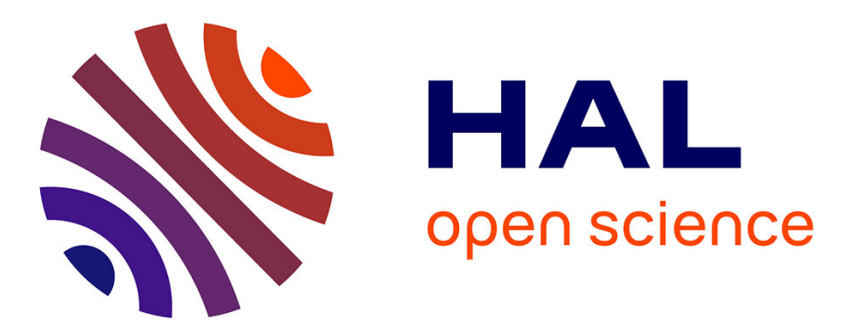

\title{
Imidazoline synthesis: mechanistic investigations show that Fe catalysts promote a new multicomponent redox reaction
}

Guillaume Coin, Patrick Dubourdeaux, Pierre-Alain Bayle, Colette Lebrun, Pascale Maldivi, Jean-Marc Latour

\section{To cite this version:}

Guillaume Coin, Patrick Dubourdeaux, Pierre-Alain Bayle, Colette Lebrun, Pascale Maldivi, et al.. Imidazoline synthesis: mechanistic investigations show that Fe catalysts promote a new multicomponent redox reaction. Dalton Transactions, 2021, 50 (19), pp.6512-6519. 10.1039/d1dt00919b . hal-03230320

\author{
HAL Id: hal-03230320 \\ https://hal.science/hal-03230320
}

Submitted on 18 Nov 2021

HAL is a multi-disciplinary open access archive for the deposit and dissemination of scientific research documents, whether they are published or not. The documents may come from teaching and research institutions in France or abroad, or from public or private research centers.
L'archive ouverte pluridisciplinaire HAL, est destinée au dépôt et à la diffusion de documents scientifiques de niveau recherche, publiés ou non, émanant des établissements d'enseignement et de recherche français ou étrangers, des laboratoires publics ou privés. 


\section{Imidazoline Synthesis: Mechanistic Investigations Show that Fe Catalysts Promote a New Multicomponent Redox Reaction}

Received 00th January 20xx, Accepted 00th January 20xx DOI: $10.1039 / x 0 x x 00000 x$

\author{
Guillaume Coin, ${ }^{[a, b]}$ Patrick Dubourdeaux, ${ }^{[a]}$ Pierre-Alain Bayle, ${ }^{[c]}$ Colette Lebrun, ${ }^{[d]}$ Pascale \\ Maldivi* $^{[\mathrm{d}]}$ and Jean-Marc Latour* ${ }^{[\mathrm{a}]}$
}

\section{Introduction}

Imidazolines are a class of compounds of strong interest in pharmacy $^{1,2}$ and medicine ${ }^{3,4}$ which is continuously enhanced by new developments, as for example for imaging ${ }^{5,6}$ and antibacterial ${ }^{7}$ purposes. Similarly, their established industrial significance ${ }^{8,9}$ has been recently reinforced by new applications as ligands for enantioselective catalysis ${ }^{10}$ as well as corrosion additives. ${ }^{11}$ As a consequence of this continuous and renewed importance, a constant effort for developing new synthetic methods of imidazoline is pursued. ${ }^{8,12-14}$ Many imidazoline syntheses have been proposed starting from either dinitrogen derivatives (i.e. diamines, amidines) or unsaturated nitrogen compounds (i.e. imines, cyanides, isocyanides, amides). Another method that is comparatively less developed consists in the nucleophilic opening of an aziridine by a Lewis acid (L. A., i.e. $\mathrm{BF}_{3} \cdot \mathrm{OEt}_{2},{ }^{15} \mathrm{Bi}(\mathrm{OTf})_{3}{ }^{16} \mathrm{TiF}_{4}{ }^{17}$ or HOTf, ${ }^{18,19}$ Scheme 1 and Scheme S1) and trapping of the resulting cationic intermediate by a nitrile. A further development of these synthetic methods has been the introduction of multicomponent reactions (MCR) based on a carbonyl/amine/isonitrile

\footnotetext{
a. Univ. Grenoble Alpes, CEA, CNRS, IRIG - LCBM / pmb, F-38000 Grenoble, France E-mail: jean-marc.latour@cea.fr.

b. Univ. Grenoble Alpes, CNRS, UMR 5250, DCM, F-38000 Grenoble, France

c. Univ. Grenoble Alpes, CEA, IRIG, MEM, F-38000 Grenoble, France.

d. Univ. Grenoble Alpes, CEA, CNRS, IRIG - SyMMES, F-38000 Grenoble, France

E-mail: pascale.maldivi@cea.fr.

†Electronic supplementary information (ESI) available: Experimental details (synthesis and catalysis procedures, imidazoline characterization data, ${ }^{1} \mathrm{H}$ and ${ }^{15} \mathrm{~N}$ NMR data) and computational details (energetic profiles, geometrical features and spin densities, charges and cartesian coordinates for key intermediates. See DOI: $10.1039 / x 0 \times x 00000 x$
}

combination ${ }^{20,21}$ or the association of two imines, $\mathrm{CO}$ and an acid chloride ${ }^{22,23}$ or the addition of an imine to an aziridine. ${ }^{24}$

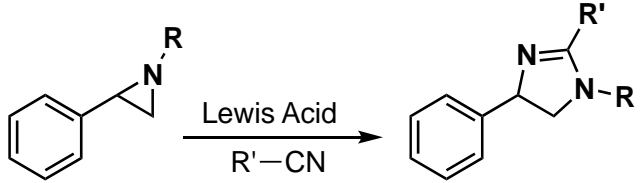

Scheme 1. Imidazoline synthesis through aziridine opening. ${ }^{14}$

We recently developed integrated experimental ${ }^{25-28}$ and theoretical ${ }^{26-29}$ studies of styrene aziridination through Fe-catalyzed nitrene transfer (Scheme 2a). These studies eventually revealed that Fe-catalyzed aziridination is governed by the electron affinity of the Fe-imide active species. ${ }^{28}$ This conclusion was based on the study of mononuclear (1a) and dinuclear (1b) Fe complexes of aminophenol ligands ${ }^{26,27}$ (Figure 1) and mononuclear complexes of nitrogen ligands. ${ }^{28}$

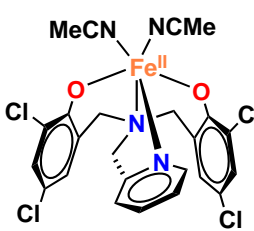

1a

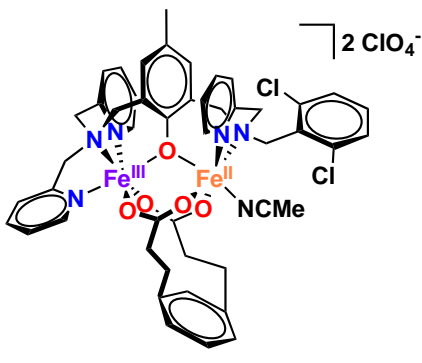

$1 b$
Figure 1. Structures of the catalysts used in this study $y^{27,30}$ 
a)

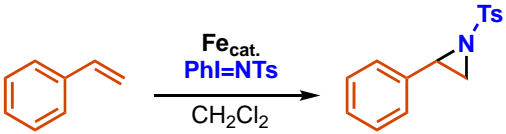

b)

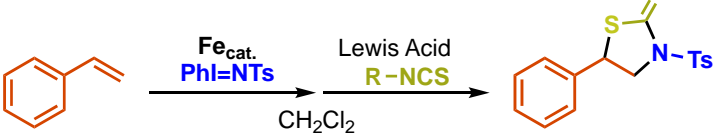

c)

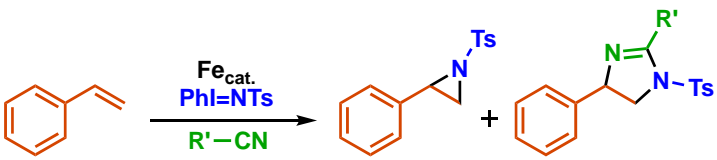

d)

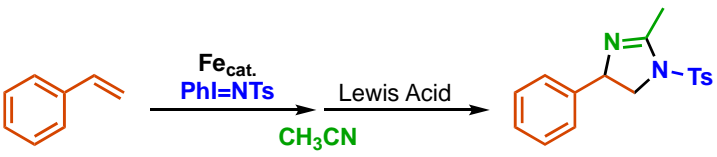

Scheme 2. Styrene aziridination and its coupling to aziridine opening $\left(R\right.$ and $R^{\prime}=$ aryl or alkyl). ${ }^{28,31}$

In addition, we reported a one-pot synthesis of 2-iminothiazolidines where the aziridination run in dichloromethane (DCM) is coupled to aziridine opening by a Lewis acid and trapping of the resulting cation by an isothiocyanate (Scheme $2 \mathrm{~b}$ ) in a Domino Ring Opening Cyclization (DROC). ${ }^{31}$ In the course of these studies, we observed that when the aziridination was run in acetonitrile instead of DCM, imidazoline was formed in small ratio (ca $15 \%$, Scheme 2c). Moreover, we observed that imidazoline ratio can be increased up to ca $68 \%$ by the one-pot DROC procedure that we used for the synthesis of iminothiazolidine ${ }^{31}$ (Scheme $2 \mathrm{~d}$ ). This prompted us to study the mechanism of the initial formation of imidazoline in absence of L. A. (Scheme 2c) and we show that it follows a different and original MCR mechanistic pathway.

\section{Results and discussion}

\section{Ring-opening of aziridine}

In a first series of experiments, we screened various $L$. A. for the aziridine ring-opening with acetonitrile as nucleophile. 2-Phenyl- $\mathrm{N}$ tosylaziridine $\mathbf{2}$ was chosen as representative substrate ${ }^{31}$ and gave 2-(methyl)-4-phenyl-1-tosyl-4,5-dihydro-1H-imidazole $\mathbf{3}$ through aziridine opening and acetonitrile insertion. The reaction was carried out in the presence of a catalytic amount of various Lewis acids in acetonitrile under mild conditions (Table 1).

In the absence of L. A., no reaction was observed (Table 1, entry 1 ). $\mathbf{3}$ is the only product formed in presence of all Lewis Acids. It appeared that tris-chlorido complexes and cuprous salts were much less active than triflate salts of tripositive cations (Table 1, entries 2 4 vs $5-9$ ), the most active in the series being $\mathrm{Al}(\mathrm{OTf})_{3}$ (Table 1 , entry 10). This yield is comparable to literature results owing to the mild conditions used (small L.A. molecular ratio and low temperature). ${ }^{14}$ It is noteworthy that in the same reaction conditions a higher yield of iminothiazolidine is obtained ( $87 \%$ vs $70 \%),{ }^{31}$ which is consistent with the higher nucleophilicity of isothiocyanate vs acetonitrile.
Table 1. Efficiency of various Lewis acid for the ring-opening cyclization of $\mathbf{2}^{[\mathrm{a}]}$

\begin{tabular}{cccccccc}
\hline & & & & & \\
\hline
\end{tabular}

[a] Yields determined by ${ }^{1} \mathrm{H}$ NMR, using mesitylene as an internal standard. The uncertainty in these determinations is $\pm 3 \%$.

In a second series of experiments, the aziridination of styrene was run in acetonitrile using the diiron(III,II) catalyst $\mathbf{1 b}^{\mathbf{3 0}}$ (Figure 1 ) in the presence of indium or aluminum triflates (Table 2). For the sake of comparison, the reaction was run initially in absence of $L$. A. and a distribution ratio $\mathbf{2 / 3}$ of $85 / 15$ was noted as reported. ${ }^{26}$ When $\ln (\mathrm{OTf})_{3}$ was used (Table 2, entry 2), this distribution was reversed to $28 / 72$, which shows that catalytic imidazoline formation occurs in these conditions. However, the conversion into the $\mathbf{2 + 3}$ mixture was reduced as tosylamine and other products were formed. This is likely caused by the fact that the Fe imine species active in aziridination is sensitive to Lewis acids ${ }^{32,33}$ and can thus be deactivated. In addition, $\mathbf{2}$ may be opened without formation of $\mathbf{3}$ if either acetonitrile attack or cyclization is not effective. When $\mathrm{Al}(\mathrm{OTf})_{3}$ was used (Table 2, entry 4), similar results were obtained: distribution $2 / 3$ ratio $23 / 77$ with a diminished overall conversion (58\%). It follows that L. A. increase formation of imidazoline but lower the overall conversion.

To try and counter this diminished conversion, we then performed the reaction in the "1-pot 2-steps" conditions: the aziridination was run in absence of $\mathrm{M}(\mathrm{OTf})_{3}$ which was added when all $\mathrm{Phl}=\mathrm{NTs}$ was consumed. In these conditions (Table 2, entries 3 and 5) similar distribution $\mathbf{2 / 3}$ ratios ca $31 / 69$ were obtained but a better conversion was achieved ( 73 vs ca $60 \%$ ), giving a $50 \%$ overall yield of 3.

The imidazoline formed in the latter reaction conditions can therefore have two distinct origins: (i) the first reaction run in

Table 2. Aziridine vs imidazoline formation during styrene aziridination ${ }^{[\mathrm{a}]}$

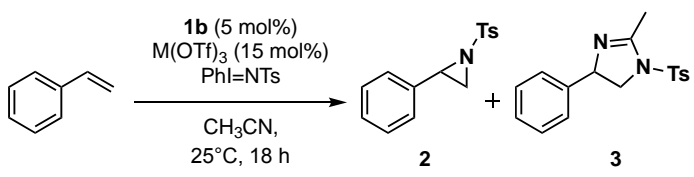




\begin{tabular}{ccccc}
\hline Entry & L. A. & $\begin{array}{c}\mathbf{2} \\
(\%)\end{array}$ & $\begin{array}{c}\mathbf{3} \\
(\%)\end{array}$ & $\begin{array}{c}\text { Conv. } \\
(\%)\end{array}$ \\
\hline 1 & None & 85 & 15 & 98 \\
2 & $\operatorname{In}(\mathrm{OTf})_{3}$ & 28 & 72 & 62 \\
$3^{[b]}$ & $\operatorname{In}(\mathrm{OTf})_{3}$ & 31 & 69 & 73 \\
4 & $\mathrm{Al}(\mathrm{OTf})_{3}$ & 23 & 77 & 58 \\
$5^{[\mathrm{b}]}$ & $\mathrm{Al}(\mathrm{OTf})_{3}$ & 32 & 68 & 73
\end{tabular}

${ }^{[a]}$ Reaction conditions : 1b / L. A. / PhINTs / styrene molar ratio $=0.05 / 0.15 / 1$ / $10, \mathrm{CH}_{3} \mathrm{CN}, 18 \mathrm{~h}, 25^{\circ} \mathrm{C}$. Conversion and $\mathbf{2} / 3$ distribution yields determined by ${ }^{1} \mathrm{H}$ NMR, using mesitylene as an internal standard. The uncertainty in these determinations is $\pm 3 \%$. ${ }^{[b]} \ln (\mathrm{OTf})_{3}$ and $\mathrm{Al}(\mathrm{OTf})_{3}$ were added after $5 \mathrm{~h}$.

absence of $\mathrm{Al}(\mathrm{OTf})_{3}$ (Scheme $2 \mathrm{c}$ ) and (ii) the opening of the aziridine in its presence (Scheme 1). The mechanism of aziridine opening by a L. A. and subsequent nucleophilic attack is well documented (Scheme S1). By contrast, the mechanism of imidazoline formation occurring in parallel to the aziridine reaction (Scheme $2 \mathrm{c}$ ) is not known. The possibility that it may be similar to the classical mechanism of Scheme S1 was suggested by the observation that aziridine opening is catalyzed by ferric triflate. ${ }^{31}$ As a matter of fact, at the end of the aziridination reaction, the catalyst is under the form of a diferric complex. The limited formation of imidazoline could therefore be due to a too limited reaction time. To evaluate this hypothesis, we repeated the aziridination reaction (in absence of $L$. A.) in the same conditions but a reaction time extended from 4 to 24 hours. This had no effect on the imidazoline content of the final reaction mixture (Table S1). This observation suggests that imidazoline is not formed in parallel to aziridination (Scheme 2c) through aziridine opening by the aziridination catalyst but by a different and unknown mechanism, which prompted us to investigate it.

\section{Identification of the imidazoline isomer}

As a preamble to the mechanistic study, it was necessary to identify which imidazoline isomer was formed in parallel to the aziridination reaction. As a matter of fact, the imidazoline chemical nature was deduced from mass spectrometry (Figures S1 and S2) and ${ }^{1} \mathrm{H}$ and ${ }^{13} \mathrm{C}$ NMR (Figures S3-S7) analyses. However, neither of these techniques could discriminate easily between the two possible isomers which differ by the linkage of the NTs group either to $C_{\alpha}$ or to $\mathrm{C}_{\beta}$ of styrene (Scheme 3).

Knowledge of this position will be mechanistically insightful since it will inform on the site of nitrene attack. To investigate it, we resorted to ${ }^{15} \mathrm{~N}$ NMR analysis of the reaction mixture at the end of catalysis. The catalytic reaction was run with $1 \mathrm{~b}$ in usual overall conditions (room temperature, catalyst/nitrene precursor/styrene: $0.05 / 1 / 10$, acetonitrile). The isotopic content of the nitrene precursor was varied by using either $\mathrm{Phl}={ }^{14} \mathrm{NTs}$ or the combination $\mathrm{Phl}(\mathrm{OAc})_{2} / \mathrm{Ts}^{15}{ }^{15} \mathrm{NH}_{2}$. A complete ${ }^{1} \mathrm{H}$ and ${ }^{13} \mathrm{C} \mathrm{NMR}$ study of the isolated imidazoline led us to assign the three protons of the cycle and the methyl group at $\delta$ ] $=4.96\left(\mathrm{H}_{\mathrm{a}}\right), 4.17\left(\mathrm{H}_{\mathrm{c}}\right), 3.45\left(\mathrm{H}_{\mathrm{b}}\right)$ and 2.32 $\left(\mathrm{CH}_{3}\right) \mathrm{ppm}$, respectively (Figure S7). Figure $\mathrm{S} 8$ presents the ${ }^{15} \mathrm{~N} N M R$ spectrum of the catalytic solution after separation of the catalyst. Three signals were detected at $\delta=85.2,93.8$ and $148.6 \mathrm{ppm}$ which are assigned to the NTs groups of the aziridine 2, tosylamine and imidazoline 3, respectively. The ${ }^{1} \mathrm{H}-{ }^{15} \mathrm{~N} 2 \mathrm{D}$ spectrum of the catalytic solution obtained with $\mathrm{Phl}(\mathrm{OAc})_{2} / \mathrm{Tss}^{15} \mathrm{NH}_{2}$ (Figure 2) exhibits strong correlations of the imidazoline ${ }^{15} \mathrm{NTs}$ with the signals assigned to
$\mathrm{CH}_{3}$ at $2.32 \mathrm{ppm}$ and $\mathrm{H}_{\mathrm{c}}$ at $4.17 \mathrm{ppm}$. Consistently, strong ${ }^{15} \mathrm{~N}$ couplings are detected for both resonances in the ${ }^{1} \mathrm{H}$ NMR spectra (Figure 3). This indicates that the ${ }^{15} \mathrm{NTs}$ is bound to styrene $\mathrm{C}_{\beta}$ (isomer $3 \mathrm{~b}$ ). This observation is consistent with the mechanism proposed for aziridination by these catalysts ${ }^{26}$ which

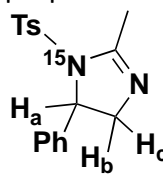

3a

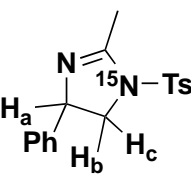

$3 \mathbf{b}$
Scheme 3. Structures of the two possible imidazoline isomers: 3a (2-methyl-3-tosyl-4phenyl-1,3-imidazoline) and 3b (2-methyl-3-tosyl-5-phenyl-1,3-imidazoline).

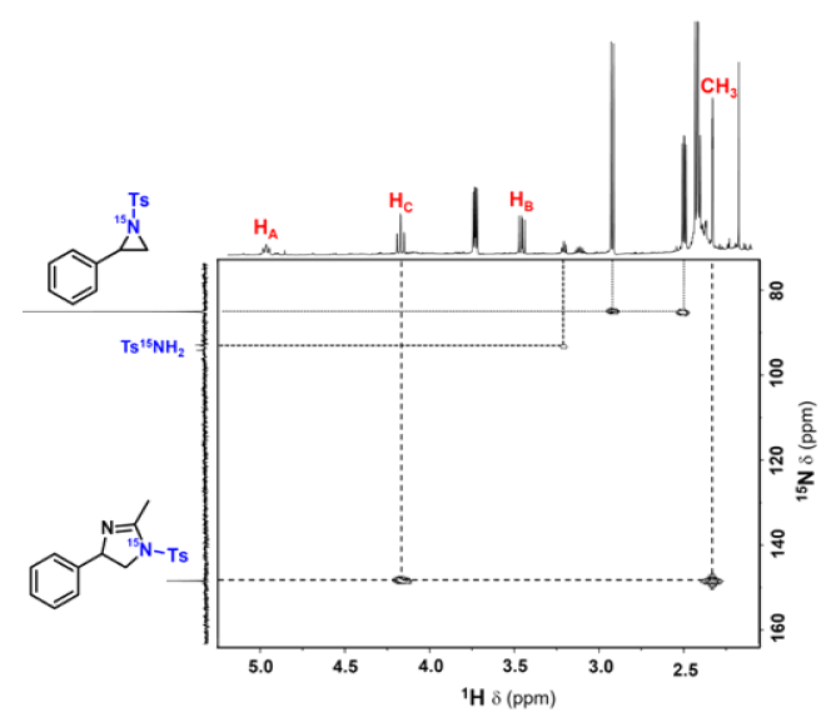

Figure $2 .{ }^{1} \mathrm{H}-{ }^{15} \mathrm{~N} 2 \mathrm{D}$ NMR spectrum of the final catalytic solution containing a mixture of 2, $\mathbf{3}$ and $\mathrm{TsNH}_{2}$ (after elimination of catalyst $\mathbf{1 b}$ ).

implies an initial attack of styrene $C_{\beta}$ onto the imido nitrogen. The full characterization of $\mathbf{3}$ allowed us to investigate its mechanism of formation.

\section{Catalytic experiments}

In a third series of experiments (Table 3), we investigated whether imidazoline formation and nitrene transfer are strictly linked by changing the reaction medium. In pure DCM (Entry 7) only aziridine was formed of course. Working in pure MeCN (Entry 1) gave a $2 / 3$ ratio of $84 / 16$. This ratio was not affected when the $\mathrm{MeCN}$ content was halved (Entry 2). By contrast, adding the same amount of $\mathrm{MeCN}$ after the aziridination reaction has subsided (Entry 8) decreased imidazoline formation four times. No further effect was observed upon addition of a MeCN/THF mixture in the same conditions (Table 4, entry 1). This shows that most imidazoline formation is linked to nitrene transfer. Then we decreased the MeCN content in DCM systematically from $25 \%$ to $0.1 \%$ (Entries 3 - 6). When MeCN content was $11 \%$, the $2 / 3$ ratio was not affected (Entries 3, 4). By contrast, when it reached $1 \%$, only $3 \%$ imidazoline were formed and traces were barely detected at $0.1 \% \mathrm{MeCN}$ in DCM. This shows that full formation of imidazoline in the present conditions (styrene 10 eq vs Phl=NTs) requires that the $\mathrm{MeCN}$ content be as high as 10 eq vs styrene. 

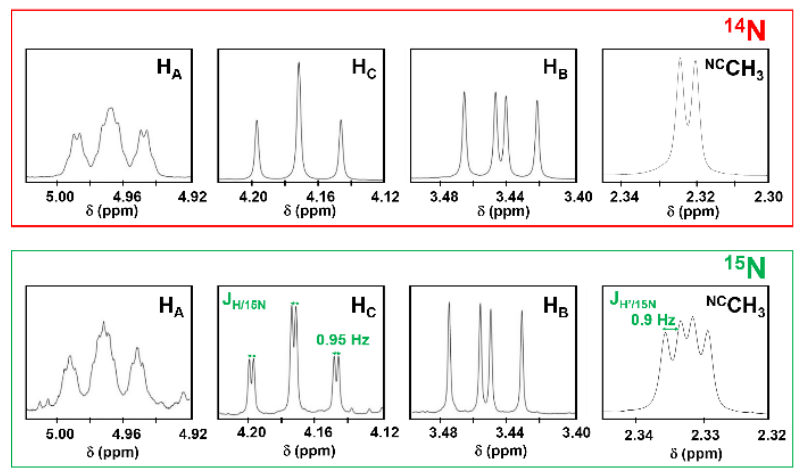

Figure $3 .{ }^{14} \mathrm{~N}$ vs ${ }^{15} \mathrm{~N}{ }^{1} \mathrm{H}$ NMR spectra of $\mathrm{H}_{\mathrm{A}}, \mathrm{H}_{\mathrm{B}}, \mathrm{H}_{\mathrm{C}}$ and $\mathrm{CH}_{3}$ protons (see Scheme 3 for assignments).

Table 3. Influence of solvent composition on imidazoline formation ${ }^{[a]}$

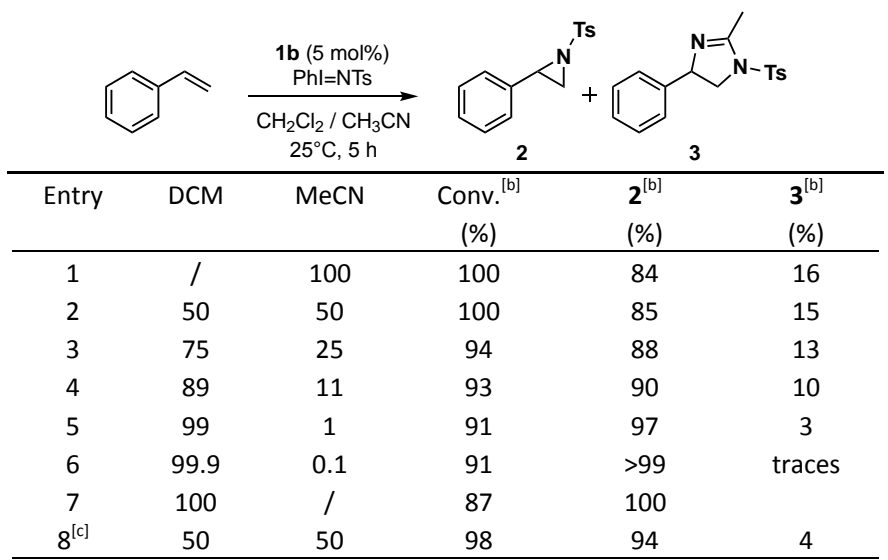

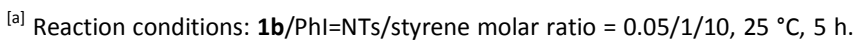

[b] Yield based on ${ }^{1} \mathrm{H}$ NMR analysis of the reaction mixture, using mesitylene as internal standard. The uncertainty in these determinations is $\pm 3 \%$. ${ }^{[c]} \mathrm{MeCN}$ was added after $5 \mathrm{~h}$ and the reaction mixture was stirred for another $5 \mathrm{~h}$.

Our study of the mechanism of amidine formation through MeCN insertion revealed that in similar conditions THF abolished amidine formation by blocking acetonitrile binding to $\mathbf{1 b}$, thereby demonstrating that $\mathrm{MeCN}$ binds to the Fe catalyst. ${ }^{34}$ To investigate whether MeCN binding is required to form imidazoline, we performed a fourth series of experiments (Table 4) in which the reaction medium was MeCN/THF mixtures of variable compositions. IWe showed earlier that THF can be $\alpha$-aminated to 2tosylaminotetrahydrofuran 4 (Scheme S2) in the same conditions using $\mathbf{1 b}$ as catalyst. ${ }^{35}$ In the present series of experiments, we anticipated that THF binding to Fe would block acetonitrile binding and potentially affect the formation of 3 and thereby the $2 / 3$ ratio. Table 4, entries 2-6 show that progressive inclusion of THF in the reaction mixture from 10 up to $50 \%$ leads to increased formation of 4 from 61 up to $87 \%$ at the expense of 2 and 3. But the composition of the $2 / 3$ mixture $(88 \pm 2 / 12 \pm 2)$ is essentially unaffected. The retention of $\mathbf{2} / \mathbf{3}$ ratio in presence of THF indicates that $\mathbf{3}$ is formed without acetonitrile binding to Fe. The diminished production of the $2 / 3$ mixture in presence of THF confirms that both $\mathbf{2}$ and $\mathbf{3}$ are formed during the nitrene transfer.

Finally, in a fifth series of experiments, we studied the nitrile influence on imidazoline/aziridine distribution in the aziridination reaction (Table S2). Catalytic experiments were thus run in usual conditions using various nitriles $\mathrm{R}-\mathrm{C} \equiv \mathrm{N}, \mathrm{R}=t \mathrm{Bu}, \mathrm{Me}$ and $\mathrm{Ph}$. The same distribution was obtained, and the absence of inductive effects goes against the possibility that the nitrile reacts with a cationic intermediate, thereby contrasting the classical mechanism (Scheme S1).

Table 4. Influence of THF on imidazoline formation ${ }^{[a]}$

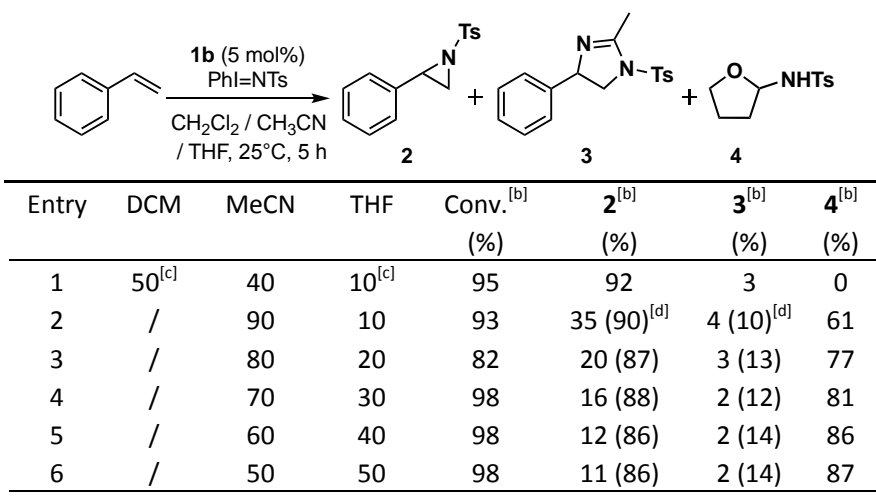

${ }^{\text {[a] }}$ Reaction conditions: $\mathbf{1 b} / \mathrm{Phl}=\mathrm{NTs} /$ styrene molar ratio $=0.05 / 1 / 10,25^{\circ} \mathrm{C}, 5 \mathrm{~h}$.

${ }^{\text {[b] }}$ Yield based on ${ }^{1} \mathrm{H}$ NMR analysis of the reaction mixture, using mesitylene as internal standard. The uncertainty in these determinations is $\pm 3 \%$. ${ }^{[c]} \mathrm{MeCN}$ was added after $5 \mathrm{~h}$ and the reaction mixture was stirred for another $5 \mathrm{~h} .{ }^{[\mathrm{d}]}$ In parentheses aziridine and imidazoline distribution.

\section{DFT calculations}

In order to uncover this different mechanism, we turned to DFT modelling. As a matter of fact, our recent investigations of Fecatalyzed aziridination revealed that DFT calculation of reaction profiles was instrumental to decipher the aziridination mechanism as they gave rise to a remarkable consistency with experiments. ${ }^{26-28}$ Furthermore, using the same approach, we analyzed very recently the far more complex mechanism of amidination ${ }^{34}$ combining nitrene transfer and nitrile insertion, which is especially relevant to the present purpose. Such reactivity calculations using the hybrid B3LYP functional are impracticable for catalyst $\mathbf{1 b}$ because of the size of the system combined to the multiplicity of spin states of both Fe. ${ }^{35,36}$ Therefore, they were performed on the mononuclear catalyst 1a. This is justified by the fact, as abovementioned, that both catalysts $\mathbf{1 a}$ and $\mathbf{1 b}$ give overall similar reactivity for aziridine vs imidazoline formation. ${ }^{26}$ Indeed other relevant mononuclear models keeping only the Fe ${ }^{\mathrm{IV}} \mathrm{NTs}$ side proved to be difficult to design, mainly because the two iron atoms share three ligands : the phenolate oxygen and two carboxylates which play a critical role in balancing the charges of the complex. In addition, the dinuclear catalyst $\mathbf{1 b}$ was shown to operate on either a $\mathrm{Fe}^{\mathrm{IV} 36}$ or a $\mathrm{Fe}^{\mathrm{V} 35}$ active species. This was taken into account in the computations by considering both $\mathrm{Fe}^{\mathrm{IV}}(=\mathrm{NTS})$ and $\mathrm{Fe}^{\mathrm{V}}(=\mathrm{NTs})$ active species derived from $1 \mathrm{a}$ as in our investigation of amidine formation. ${ }^{34}$ Such highvalent Fe-imido species are well known to exhibit some radical character on the nitrogen atom, ${ }^{26,29,35,36}$ but for the sake of clarity we prefer this notation based on Fe oxidation state. Accordingly, we used the same computational approach as developed in these latter mechanistic studies. ${ }^{34}$

Two main possibilities may be envisaged (Scheme 4) for the insertion of acetonitrile: (i) acetonitrile attacks the Fe-bound NTs through its $C_{s p}$ carbon to generate a metallacycle (diazaferracyclobutane) as a new nitrene able to attack the olefin, 
or (ii) acetonitrile attacks through its nitrogen the $\mathrm{C}_{\alpha}$ [carbon of the first aziridination intermediate. ${ }^{26,28}$

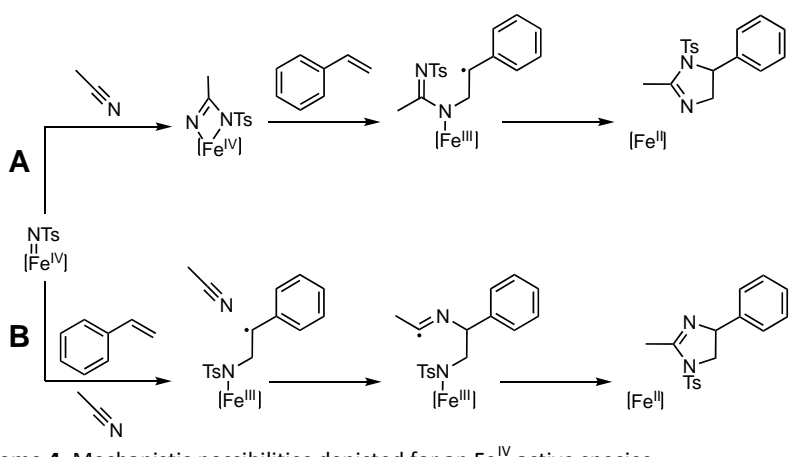

Scheme 4. Mechanistic possibilities depicted for an $\mathrm{Fe}^{\mathrm{IV}}$ active species.

i) Formation of a metallacycle. The formation of a metallacycle intermediate was considered first (Scheme 4A). Such a process was indeed demonstrated in the case of copper compounds. ${ }^{37}$ However, it can be ruled out in the present case on two different grounds. (i) Indeed, we showed in our previous study on amidine formation ${ }^{34}$ that the activation energy for formation of this metallacycle from the imido $\mathrm{Fe}^{\mathrm{v}}$ intermediate is $\geq 20 \mathrm{kcal} \mathrm{mol}^{-1}$ higher than the low energy pathways leading to direct aziridination. ${ }^{26}$ Our present calculations (Figure S9 and Table S3) reveal that the formation of the metallacycle from an imido $\mathrm{Fe}^{\mathrm{IV}}$ intermediate also requires a high activation energy $\left(\geq 20 \mathrm{kcal} \mathrm{mol}^{-1}\right)$. An analogous result had been obtained from an imido $\mathrm{Fe}^{\mathrm{IV}}$ intermediate by Jenkins and coll. ${ }^{38}$ for Fe macrocyclic catalysts. (ii) In both $\mathrm{Fe}^{\mathrm{IV}}$ or $\mathrm{Fe}^{\mathrm{V}}$ active models, the resulting metallacycle bears a radical character on the $\mathrm{N}$ atom issued from acetonitrile that should thus attack styrene $\mathrm{C}_{\beta}$ @ ]carbon which is the prefered site of attack in the aziridination. ${ }^{26}$ But, from the present NMR experiments, we know that this $C_{\beta}$ atom is bound to the NTs group in the formed imidazoline.

ii) Attack of an aziridination intermediate. The second possibility is therefore to proceed with the first step of aziridination to the first intermediate bearing a radical on styrene $C_{\alpha}$ atom ${ }^{26}$ and consider that acetonitrile attacks this radical before the closure step of the aziridine (Scheme 4B). Several active species can be considered depending on the $\mathrm{Fe}$ oxidation state and potential acetonitrile binding. We showed earlier that acetonitrile does not bind significantly to $\mathrm{Fe}^{\mathrm{IV}}=\mathrm{NTs}^{26}$ but that it does to $\mathrm{Fe}^{\mathrm{V}}=\mathrm{NTs}{ }^{34}$ owing to the higher acidity of the metal. Therefore, three active species must be considered, i.e. $\left[\mathrm{Fe}^{\mathrm{IV}}(=\mathrm{NTs})\right],\left[\mathrm{Fe}^{\mathrm{V}}(=\mathrm{NTs})\right]$ and $\left[\mathrm{Fe}^{\mathrm{V}}(=\mathrm{NTs})\left(\mathrm{CH}_{3} \mathrm{CN}\right)\right]$. Previous calculations have shown that these active species have widely different electron affinities. $\left[\mathrm{Fe}^{\mathrm{V}}=\mathrm{NTs}\right]$ has a very high electron affinity $\left(143 \mathrm{kcal} \mathrm{mol}^{-1}\right)^{35}$ which excedes the calculated ionization potential of styrene $\left(139 \mathrm{kcal} \mathrm{mol}^{-1}\right) \cdot{ }^{28}$ As a consequence, an easy electron transfer from styrene would occur to form a cationic intermediate. Our experimental studies (Table 3) have failed to evidence an electro-inductive influence in imidazoline formation. This rules out the potential acetonitrile attack of a cationic intermediate, and hence, the intervention of $\mathrm{Fe}^{\mathrm{V}}=\mathrm{NTS}$ in imidazoline formation. Moreover, this intermediate should be very short-lived, the overall process leading to the aziridine without barrier.
In addition, our experiments using acetonitrile/THF solvent mixtures showed that THF did not change the aziridine/imidazoline ratio, thereby indicating that acetonitrile binding did not take part in the process. This excludes the involvement of the adduct

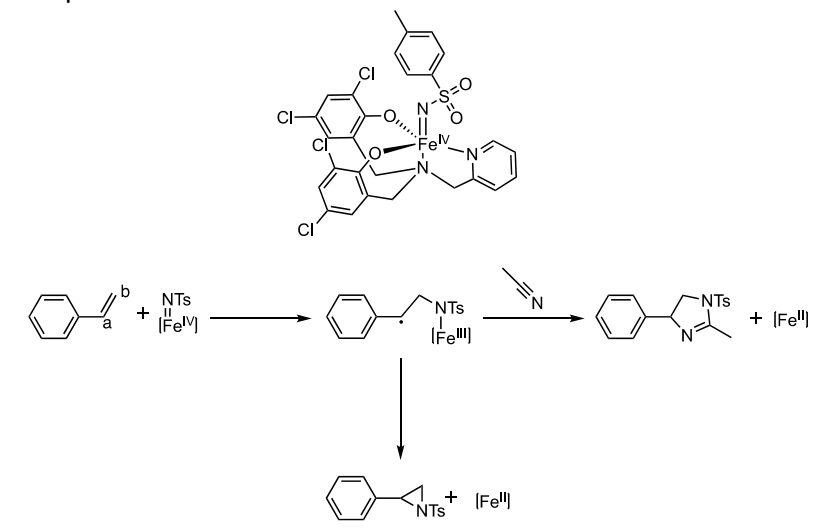

Scheme 5. Top: model active species ( $\mathrm{Fe}^{\mathrm{IV}}$ ) derived from 1a; bottom: proposed pathway for aziridination and imidazoline formation.

$\left[\mathrm{Fe}^{\mathrm{V}}=\mathrm{NTs}\left(\mathrm{CH}_{3} \mathrm{CN}\right)\right]$ as active species. From these observations, it appears that imidazoline formation is linked only to aziridination catalyzed by the $\left[\mathrm{Fe}^{\mathrm{IV}}=\mathrm{NTs}\right]$ active species.

This reaction is sketched in Scheme 5 together with the molecular structure of the model [ $\left.\mathrm{Fe}^{\mathrm{IV}}=\mathrm{NTs}\right]$ active species. The corresponding thermodynamic profile leading to $\mathbf{3}$ from the Fe ${ }^{\text {III }}$ intermediate Int0 is represented in Figure 4. Only the quintet state is shown here as we have observed that on the triplet surface a much higher activation barrier is required to yield the first intermediate. ${ }^{26}$

The formation of imidazoline from Int0 involves a two-step process. A first step leads to intermediate Int1 (Figure 4, Tables S4 and S5) resulting from the bonding of acetonitrile $\mathrm{N}$ to styrene $\mathrm{C}_{\alpha}$ [?]carbon. From this intermediate, a cyclization could readily occur to form imidazoline weakly coordinated by one tosyl oxygen to the $\mathrm{Fe}^{\prime \prime}$ ion. To gain more information on the actual electronic features of the key species, we analyzed their Mulliken charges and spin densities (Table S6). The initial species Int0, which is the intermediate in the aziridination process, ${ }^{26}$ is a high spin $\mathrm{Fe}^{\text {III }}$ complex antiferromagnetically coupled to the radical on styrene $C_{\alpha}$. The acetonitrile attack yields Int1, in which the spin densities clearly point to a reduction of the Fe ion to a high spin Fe" state. No other radical character can be detected. The $\mathrm{C}-\mathrm{N}$ (from acetonitrile) bond length in intermediate Int 1 is identical ( $1.15 \AA$ ) to that in isolated acetonitrile, showing that the triple bond is still present while a new $\mathrm{C}_{\text {] }}-\mathrm{N}$ bond at $1.44 \AA$ is formed. This points to a tetravalent nitrogen atom which indeed exhibits a positive partial charge. It is worth 

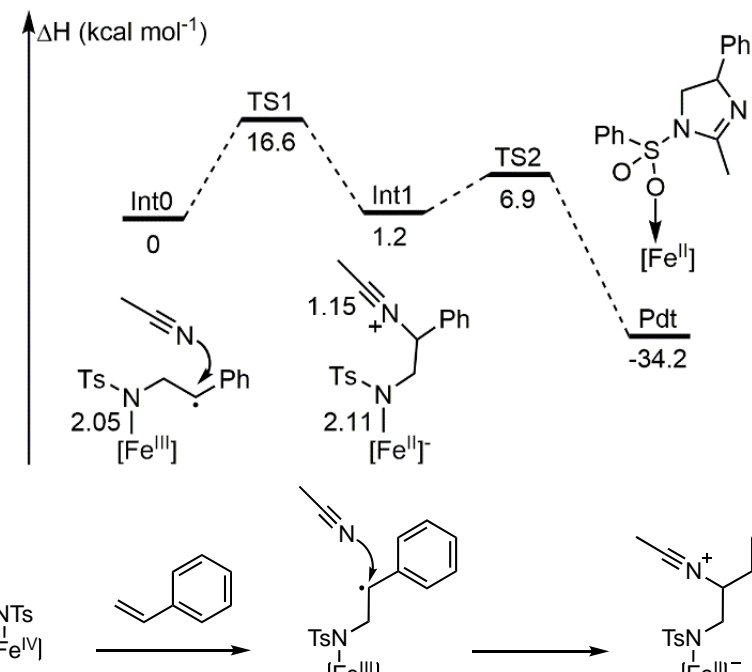

Figure 4. Two-step reaction pathway for imidazoline cyclization from acetonitrile attack on the aziridination intermediate. Calculations with B3LYP-D3/BS2-COSMO//B3LYP-D3BS1. Enthalpies in $\mathrm{kcal} \mathrm{mol}^{-1}$. Some selected bond distances $(\AA)$ are shown.
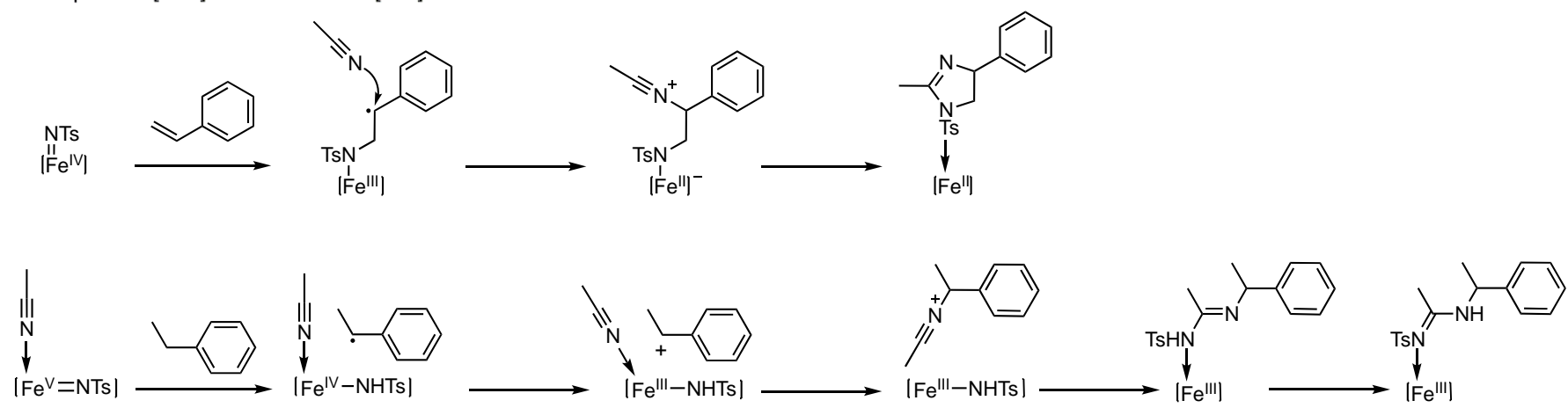

Scheme 6. Comparison of the mechanisms of formation of imidazoline (top) and amidine (bottom)

noting that in this process acetonitrile attack induces the reduction of the Fe center by the benzyl radical. Finally the cyclization leads to imidazoline with a C-N (from initial acetonitrile) bond length of $1.28 \AA$ consistent with a double bond, and a $\mathrm{C}_{\alpha}-\mathrm{N}$ bond length of $1.47 \AA$ consistent with a $\mathrm{C}-\mathrm{N}$ single bond. Dissociation of the imidazoline from the $\mathrm{Fe}^{\prime \prime}$ complex (not shown on Figure 4) brings a further stabilization by a very weak enthalpic value of $-1.8 \mathrm{kcal} \mathrm{mol}^{-1}$. The cyclization process from Int 1 does not require a high activation enthalpy. By contrast, an enthalpic barrier of $16.6 \mathrm{kcal} \mathrm{mol}^{-1}$ is associated to acetonitrile addition to the benzyl radical which is clearly the determining step. This enthalpy value is higher than the ones involved in aziridination processes, all being less than $10 \mathrm{kcal}$ $\mathrm{mol}^{-1}$ at the same computational level. ${ }^{26}$ However, being the solvent, acetonitrile is in huge excess $\left(1.410^{4}\right.$ eq vs $\mathbf{1 b}$ ) which renders the imidazoline pathway competitive to aziridine formation on statistical criteria. These opposite factors are reflected in the aziridine vs imidazoline ratio (ca 6) strongly in favor of aziridine.

\section{General Mechanistic Considerations}

To summarize, our mechanistic studies have revealed that imidazoline can be accessed through an unprecedented multicomponent redox reaction where free acetonitrile traps an intermediate benzylic radical. Acetonitrile insertion into a product of nitrene transfer has been described only in a very limited number of cases: allylic amination catalyzed by $\mathrm{Mn}$ or Fe porphyrins, ${ }^{39}$ and aliphatic aminations catalyzed by copper ${ }^{40}$ and iron $^{34}$ complexes. In all cases these reactions led to an amidine derivative. A similar process involving acetonitrile insertion competing with aziridination to form an imidazoline had never been described.
As far as mechanisms are concerned, it is clear that acetonitrile insertion through formation of metallacyclobutane (Scheme 4) is possible but it is generally unfavorable with respect to other pathways. ${ }^{34,38}$ Albeit acetonitrile insertions to form imidazoline and amidine bear overall resemblance, their mechanisms depart in many respects as highlighted in Scheme 6. The first difference resides in the oxidation state of the catalyst: as shown in the present work, imidazoline formation is catalyzed by the $\mathrm{Fe}^{\mathrm{IV}}$ species, whereas amidine formation is catalyzed by an acetonitrile-bound $\mathrm{Fe}^{\mathrm{V}}$ catalyst. ${ }^{34}$ The second difference stays in the nature of the intermediate attacked by acetonitrile: a radical for imidazoline vs a cation for amidine. The last difference is to be found in the nature of the attacking acetonitrile molecule which comes from the solvent in the case of imidazoline, whereas it is bound to $\mathrm{Fe}$ in the case of amidine. There is a strong intrinsic consistency among these features: aliphatic amination requires a more powerful oxidation catalyst than aziridination, i.e. an $\mathrm{Fe}^{\mathrm{V}}$ species as opposed to an $\mathrm{Fe}^{\mathrm{IV}}$ one. This $\mathrm{Fe}^{\mathrm{V}}$ species performs a $\mathrm{H}^{\bullet}$ abstraction generating a benzyl radical and an $\mathrm{Fe}^{\mathrm{IV}}$ intermediate, powerful enough to further oxidize the radical to a cation. This further oxidation is not possible by the intermediate $\mathrm{Fe}^{\text {III }}$ resulting from the aziridination first step. In addition, this $\mathrm{Fe}^{\mathrm{V}}$ catalyst is acidic enough for acetonitrile to bind it, whereas it cannot bind the $\mathrm{Fe}^{\mathrm{IV}}$ catalyst. $^{26,27}$ Consequently, the acetonitrile molecule attacking the benzyl cation comes from Fe coordination sphere, whereas that attacking the benzyl radical comes from the solvent.

Noteworthy, in both cases, all these events occur within or close to the Fe coordination sphere. As a further comparison between the two processes, the extent of acetonitrile insertion deserves to be commented. Indeed, ca $15 \%$ of imidazoline is formed (vs $85 \%$ aziridine) as opposed to ca $88 \%$ of amidine (vs 
$12 \%$ of amine). This limited imidazoline formation can be explained by the fact that acetonitrile insertion competes with closure of the aziridine ring which generally implies a small activation barrier. ${ }^{28,38}$ By contrast, in the case of amidine formation, acetonitrile insertion competes with the radical rebound process which requires a substantial activation energy $\left(>15 \mathrm{kcal} \mathrm{mol}^{-1}\right)^{34,41}$

\section{Conclusion}

Combined experimental and computational studies of these solvent insertion reactions allow to reach a detailed molecular understanding of these multicomponent reactions and to delineate the main energetic factors orienting the selectivity toward insertion. Moreover, by coupling this process to classical aziridine opening by a nucleophile in "one pot two steps" DROC process, it is possible to enhance imidazoline formation. This could pave the way to developing this approach to address solvent incorporation as a synthetic tool.

\section{Author Contributions}

G.C., P.D., P.-A.B. and C.L. performed and analyzed experiments. P.M. designed, performed and analyzed computations. G.C., P.M. and J.-M.L. designed the work and wrote the manuscript.

\section{Conflicts of interest}

There are no conflicts to declare.

\section{Acknowledgments}

G. C. and J.-M. L. thank the French National Agency for Research (ANR) "programme Labex" (Labex ARCANE and CBH-EURGS (ANR-17-EURE-0003) for funding. This work was performed thanks to HPC resources from GENCI (IDRIS and CINES, grants A0060807648 and A0080807648).

\section{References}

1 M. Krasavin, Eur. J. Med. Chem., 2015, 97, 525-537.

2 M. Krasavin, Chem. Heterocycl. Compd., 2017, 53, 240255.

3 J. A. Lowry and J. T. Brown, Clin. Toxicol., 2014, 52, 454469.

4 F. Saczewski, A. Kornicka and L. Balewski, Expert Opin. Ther. Pat., 2016, 26, 1031-1048.

5 Q. Xu, C. H. Heo, G. Kim, H. W. Lee, H. M. Kim and J. Yoon, Angew. Chem. Int. Ed., 2015, 54, 4890-4894.

6 P. Zhang, H. Wang, Y. Hong, M. Yu, R. Zeng, Y. Long and J. Chen, Biosens. Bioelectron., 2018, 99, 318-324.

$7 \quad$ M. S. Faillace, A. P. Silva, A. L. Alves Borges Leal, L. M. da Costa, H. M. Barreto and W. J. Pelaez, ChemMedChem, 2020, 15, 851-861.

8 H. Liu and D.-M. Du, Adv. Synth. Catal., 2009, 351, 489519.
9 $56,211-22$

R. Tyagi, V. K. Tyagi and S. K. Pandey, J. Oleo Sci., 2007,

10 S. Nakamura, K. Hyodo, M. Nakamura, D. Nakane and H. Masuda, Chem. Eur. J., 2013, 19, 7304-7309.

11 K. Zhang, B. Xu, W. Yang, X. Yin, Y. Liu and Y. Chen, Corros. Sci., 2015, 90, 284-295.

12 R. D. Crouch, Tetrahedron, 2009, 65, 2387-2397.

13 B. H. Rotstein, S. Zaretsky, V. Rai and A. K. Yudin, Chem. Rev., 2014, 114, 8323-8359.

14 M. S. Al Mehedi and J. J. Tepe, Adv. Synth. Catal., 2020, 362, 4189-4225.

15 S. Gandhi, A. Bisai, B. A. B. Prasad and V. K. Singh, J. Org. Chem., 2007, 72, 2133-2142.

16 X. Li, X. Yang, H. Chang, Y. Li, B. Ni and W. Wei, Eur. J. Org. Chem., 2011, 3122-3125.

17 T. Ishikawa, M. Yoshiki, T. Tanaka, K. Ogata, Y. Yamada and T. Hanamoto, Synth.-Stuttg., 2016, 48, 1322-1330.

18 R. Li, H. Jiang, W.-Y. Liu, P.-M. Gu and X.-Q. Li, Chin. Chem. Lett., 2014, 25, 583-585.

19 Q. Zuo, Z. Shi, F. Zhan, Z. Wang, J.-S. Lin and Y. Jiang, Tetrahedron Lett., 2019, 151576.

20 N. Elders, R. F. Schmitz, F. J. J. de Kanter, E. Ruijter, M. B. Groen and R. V. A. Orru, J. Org. Chem., 2007, 72, 6135-6142.

21 C. T. Martha, A. Heemskerk, J.-C. Hoogendoorn, N. Elders, W. M. A. Niessen, R. V. A. Orru and H. Irth, Chem.- Eur. J., 2009, 15, 7368-7375.

22 K. Worrall, B. Xu, S. Bontemps and B. A. Arndtsen, J. Org. Chem., 2011, 76, 170-180.

23 S. Bontemps, J. S. Quesnel, K. Worrall and B. A. Arndtsen, Angew. Chem. Int. Ed., 2011, 50, 8948-8951.

24 M. R. Kuszpit, W. D. Wulff and J. J. Tepe, J. Org. Chem., 2011, 76, 2913-2919.

25 F. Avenier and J.-M. Latour, Chem. Commun., 2004, 1544-1545.

26 R. Patra, G. Coin, L. Castro, P. Dubourdeaux, M. Clémancey, J. Pécaut, C. Lebrun, P. Maldivi and J.-M. Latour, Catal. Sci. Technol., 2017, 7, 4388-4400.

27 G. Coin, R. Patra, M. Clémancey, P. Dubourdeaux, J. Pécaut, C. Lebrun, L. Castro, P. Maldivi, S. Chardon-Noblat and J.M. Latour, ChemCatChem, 2019, 11, 5296-5299.

28 G. Coin, R. Patra, S. Rana, J. P. Biswas, P. Dubourdeaux, M. Clemancey, S. P. de Visser, D. Maiti, P. Maldivi and J.-M. Latour, ACS Catal., 2020, 10, 10010-10020.

29 R. Patra and P. Maldivi, J. Mol. Model., 2016, 22, 278.

30 S. Chardon-Noblat, O. Horner, B. Chabut, F. Avenier, N. Debaecker, P. Jones, J. Pécaut, L. Dubois, C. Jeandey, J.-L. Oddou, A. Deronzier and J.-M. Latour, Inorg. Chem., 2004, 43, 16381648.

31 G. Coin, O. de Ferrier de Montal, P. Dubourdeaux and J.M. Latour, Eur. J. Org. Chem., 2021, 443-448.

32 T. Devi, Y.-M. Lee, W. Nam and S. Fukuzumi, Coord. Chem. Rev., 2020, 410, 213219.

33 X. Lu, Y.-M. Lee, M. S. Seo and W. Nam, Chem. Commun., 2020, 56, 11207-11210.

34 G. Coin, P. Dubourdeaux, F. Avenier, R. Patra, L. Castro, C. Lebrun, P.-A. Bayle, J. Pécaut, G. Blondin, P. Maldivi and J.-M. Latour, ACS Catal., 2021, 11, 2253-2266.

35 E. Gouré, D. Senthilnathan, G. Coin, F. Albrieux, F. Avenier, P. Dubourdeaux, C. Lebrun, P. Maldivi and J.-M. Latour, Angew. Chem. Int. Ed., 2017, 56, 4305-4309.

36 E. Gouré, F. Avenier, P. Dubourdeaux, O. Sénèque, F. Albrieux, C. Lebrun, M. Clémancey, P. Maldivi and J.-M. Latour, 
Angew. Chem. Int. Ed., 2014, 53, 1580-1584.

37 A. Bakhoda, Q. Jiang, J. Bertke, T. R. Cundari and T. H. Warren, Angew. Chem. Int. Ed., 2017, 56, 6426-6430.

38 S. B. Isbill, P. P. Chandrachud, J. L. Kern, D. M. Jenkins and S. Roy, ACS Catal., 2019, 9, 6223-6233.

39 D. A. Evans, M. M. Faul and M. T. Bilodeau, J. Am. Chem. Soc., 1994, 116, 2742-2753.

40 V. Bagchi, P. Paraskevopoulou, P. Das, L. Chi, Q. Wang, A. Choudhury, J. S. Mathieson, L. Cronin, D. B. Pardue, T. R. Cundari, G. Mitrikas, Y. Sanakis and P. Stavropoulos, J. Am. Chem. Soc., 2014, 136, 11362-11381.

41 S. Kumar, A. S. Faponle, P. Barman, A. K. Vardhaman, C. V. Sastri, D. Kumar and S. P. de Visser, J. Am. Chem. Soc., 2014, 136, 17102-17115. 